\title{
PERBEDAAN HASIL BELAJAR SISWA YANG DIBELAJARKAN MENGGUNAKAN MODEL PEMBELAJARAN LC 5E-STAD DAN MODEL LC 5E-TPS
}

\author{
Putri Wahyuning Tyas ${ }^{1 *}$, Endang Budiasih ${ }^{2}$, Dedek Sukarianingsih ${ }^{3}$ \\ 1,2,3 Jurusan Kimia FMIPA Universitas Negeri Malang
}

\begin{abstract}
Abstrak - Penelitian ini bertujuan untuk mengetahui perbedaan hasil belajar siswa yang dibelajarkan menggunakan model pembelajaran Learning Cycle 5 fase-Student Teams Achievement Divisions (LC 5E-STAD) dengan model pembelajaran LC 5E-TPS pada materi koloid. Rancangan yang akan digunakan dalam penelitian ini adalah rancangan eksperimen semu (Quasy Experimental Design). Penelitian ini melibatkan dua kelas sebagai sampel penelitian. Dua kelas yang digunakan dalam penelitian ini merupakan kelas eksperimen. Satu kelas eksperimen diberi perlakuan berupa model pembelajaran LC 5E-STAD dan satu kelas eksperimen lainnya diberi perlakuan berupa model pembelajaran LC 5E-TPS. Instrumen yang digunakan dalam penelitian meliputi instrumen pembelajaran (Silabus, RPP, handout dan LKS) dan instrumen pengukuran (soal ulangan harian dan lembar observasi pembelajaran). Data yang diperoleh berupa penilaian keterlaksanaan proses pembelajaran, nilai afektif, nilai psikomotorik, nilai kuis dan hasil belajar dari ulangan harian Rata-rata hasil belajar siswa yang dibelajarkan dengan LC 5E-TPS adalah 81,71, lebih tinggi dari siswa yang dibelajarkan dengan LC 5E-STAD yaitu sebesar 77,83. Berdasarkan hasil penelitian, maka dapat disimpulkan bahwa hasil belajar siswa pada materi koloid yang dibelajarkan dengan LC 5E-TPS lebih baik dari pada siswa yang dibelajarkan dengan LC 5E-STAD.
\end{abstract}

Kata kunci: Hasil belajar; LC 5E-STAD; LC 5E-TPS; koloid

\begin{abstract}
This study aims to investigate the difference of learning outcomes in the colloid topic between students who taught using LC 5E-STAD and those who taught using Learning Cycle 5 fase-Think Pair Share (LC 5E-TPS) learning models. The research is a quasi experimental design. The study involved two groups which are experiment and control groups. The experiment group was taught using LC 5E-STAD and the other was taught using LC-5E TPS. Instruments that used in the study include learning instruments (syllabus, RPP, handouts and LKS) and measurement instruments (daily tests and learning observation sheets). Data obtained in the form of assessment of learning process implementation, affective value, psychomotor value, quiz score and learning result from daily test. The average learning outcomes of students who were taught by LC 5E-TPS learning model was 81.71 , higher than students who were taught by LC 5E-STAD learning models $(77,83)$. This means that the use of LC 5E-TPS fo teaching colloid is more recommended instead of using LC 5E-STAD..
\end{abstract}

Keywords: Learning outcomes; LC 5E-STAD; LC 5E-TPS; Colloid

\section{PENDAHULUAN}

Kimia merupakan salah satu cabang Ilmu Pengetahuan Alam yang mempelajari tentang sifat dari suatu materi, struktur materi, perubahan dalam materi, hukum, dan prinsip yang mendeskripsikan perubahan materi, serta konsep dan teorinya (Effendy, 2006: 1). Banyaknya materi yang harus

\footnotetext{
${ }^{*}$ Corresponding authors: Jurusan Kimia, Universitas Negeri Malang, Malang 65145, Indonesia. Email: Putriwahyuningtyas95@gmail.com
} 
dipelajari dalam kimia, menjadikan siswa mengalami kesulitan dalam mempelajarinya. Salah satu materi kimia yang dianggap sulit yaitu koloid, karena banyak istilah-istilah terasa asing bagi siswa.

Materi koloid merupakan salah satu materi kimia pada jenjang pendidikan SMA/MA/SMK. Kompetensi dasar pada materi koloid adalah mengelompokkan berbagai tipe sistem koloid, dan menjelaskan kegunaan koloid dalam kehidupan berdasarkan sifat-sifatnya (Permendikbud No. 24 tahun 2016). Masalah yang sering ditemukan dalam pembelajaran pada materi koloid adalah kurangnya kemampuan siswa dalam memahami bacaan, menganalisis informasi dan mengingat materi. Ketiga kemampuan ini secara signifikan dapat meningkatkan hasil belajar pada materi koloid (Daro'anini, dkk, 2013). Masalah tersebut yang membuat siswa mengalami kesulitan dalam mempelajari koloid. Diperkuat dengan fakta dilapangan menunjukkan bahwa metode pembelajaran yang digunakan pun masih menggunakan metode konvensional. Alternatif yang dapat digunakan untuk mengatasi ketidak tuntasan hasil belajar siswa dalam materi koloid dengan menggunakan model pembelajaran yang menekankan siswa aktif dalam proses pembelajaran. Model pembelajaran yang bersifat student centered salah satunya adalah model pembelajaran Learning Cycle (LC) (Herbandri, 2008: 26).

Model pembelajaran Learning Cycle merupakan model pembelajaran sains yang efektif dan dikenal oleh para pengajar sains. Pada mulanya Learning Cycle terdiri dari 3 fase yaitu fase penyelidikan (exploration), fase penjelasan (explanation), fase penerapan/perluasan (elaboration). Selanjutnya pembelajaran Learning Cycle ini berkembang dari 3 fase ke tahapan 5 fase. Learning Cycle 5 fase dikembangkan oleh Bybee, dkk dalam Iskandar (2011: 48). Fase engagement bertujuan mengenalkan materi yang akan dipelajari yang sifatnya memotivasi dengan cara mengaitkannya dengan hal-hal dalam kehidupan sehari-hari yang dialami dan merupakan pengalaman nyata siswa. Fase exploration bertujuan agar siswa memperoleh pengalaman belajarnya dengan menemukan fenomena, interaksi langsung dengan obyek nyata dan siswa diberikan kesempatan untuk bekerja sama untuk memecahkan masalah. Fase explanation bertujuan untuk mendorong siswa menjelaskan konsep yang telah ditemukan pada fase exploration. Fase elaboration bertujuan membantu siswa agar mampu, menerapkan konsep-konsep yang telah dipahami dengan keterampilan yang dimiliki pada situasi baru tetapi masih ada kemiripan dengan konsep yang sudah dimiliki sebelumnya. Fase evaluation bertujuan untuk melakukan mengevaluasi efektifitas fase-fase sebelumnya dan juga evaluasi terhadap pengetahuan, pemahaman konsep, atau kompetensi siswa melalui problem solving dalam konteks baru yang kadang-kadang mendorong siswa melakukan investigasi lebih lanjut (Fajaroh \& Dasna, 2007).

Pembelajaran LC-5E, menuntut siswa belajar secara mandiri, dan harus aktif dalam menggali dan memperoleh informasi. Belajar mandiri dapat menyulitkan siswa yang memiliki kemampuan rendah, dan diperlukan pembelajaran yang dapat melibatkan siswa berinteraksi dengan siswa lainnya. Model pembelajaran $L C-5 E$ juga menuntut siswa bekerja secara kooperatif dengan tidak memiliki pola tertentu, sehingga memerlukan kerja dari kooperatif lain yaitu pembelajaran kooperatif STAD dan TPS. Pembelajaran kooperatif STAD dan TPS merupakan pembelajaran kooperatif yang memiliki struktur atau pola tertentu. Model pembelajaran kooperatif $S T A D$ dan kooperatif TPS mempunyai kelebihan dan kelemahan masingmasing.

Slavin (2005: 143) menyatakan bahwa STAD merupakan model pembelajaran kooperatif yang paling sederhana dan sebuah model yang baik untuk permulaan bagi seorang guru untuk menerapkan pembelajaran kooperatif. Pelaksanaan model pembelajaran $S T A D$ meliputi 5 komponen utama yaitu: (1) presentasi kelas, (2) kelompok, (3) kuis atau tes, (4) skor kemajuan individu, (5) penghargaan kelompok. Model TPS merupakan model pembelajaran kooperatif yang dirancang untuk mempengaruhi pola interaksi siswa. Keunggulan model pembelajaran TPS adalah siswa secara individu mampu mengembangkan pemikiran karena adanya waktu berpikir, selain itu akuntabilitas juga berkembang Tahapan dalam TPS adalah thinking (berpikir), pairing (berpasangan), dan sharing (berbagi).

Perbedaan kedua model pembelajaran STAD dan TPS terletak pada banyaknya sumbangan berpikir. Dalam model pembelajaran STAD siswa berkelompok yang beranggotakan 4 sampai 5 orang sehingga sumbangan berpikir siswa lebih kompleks, sedangkan pada model pembelajaran TPS terdiri dari 2 orang sehingga sumbangan berpikir siswa lebih sedikit tetapi pada model pembelajaran TPS ini sebelum berkelompok siswa disuruh untuk berpikir terlebih dahulu. Oleh karena itu peneliti tertarik untuk 
memadukan model pembelajaran LC 5E-STAD dengan menerapkan tahap STAD pada LC 5E dan LC 5ETPS dengan menerapkan tahap TPS pada LC 5E. Hal ini dimaksudkan agar kedua model pembelajaran tersebut saling melengkapi dan dapat meningkatkan proses pembelajaran. Pemaduan model LC 5E -STAD pernah diteliti oleh Setyowati (2011) yang menunjukkan bahwa model LC 5E-STAD dapat meningkatkan prestasi belajar siswa pada materi minyak bumi. Pemaduan model LC 5E -TPS pernah diteliti oleh Jatmiko (2014) yang menunjukkan bahwa model LC 5E-TPS dapat meningkatkan prestasi belajar siswa pada materi asam basa. Untuk memperoleh hasil belajar yang memuaskan diupayakan memadukan model pembelajaran LC-5E dengan model pembelajaran kooperatif STAD dan TPS. Oleh karena itu peneliti tertarik untuk memadukan model pembelajaran LC 5E-STAD dengan menerapkan tahap STAD pada LC-5E dan LC 5ETPS dengan menerapkan tahap TPS pada LC-5E. Hal ini dimaksudkan agar kedua model pembelajaran tersebut saling melengkapi dan dapat meningkatkan proses pembelajaran.

Berdasarkan uraian tersebut, maka peneliti termotivasi untuk melihat perbedaan hasil belajar antara siswa yang dibelajarkan dengan model pembelajaran LC 5E-STAD dan siswa yang dibelajarkan dengan model pembelajaran LC 5E-TPS.

\section{METODE}

Rancangan yang akan digunakan dalam penelitian ini adalah rancangan eksperimen semu (Quasy Experimental Design), karena tidak dilakukan randomisasi sampel, tetapi digunakan kelas-kelas yang telah ada. Desain yang dipilih dalam penelitian ini adalah rancangan eksperimen semu dengan post test. Rancangan eksperimen digunakan untuk mengetahui adanya perbedaan hasil belajar siswa yang dibelajarkan menggunakan model pembelajaran LC 5E-STAD dengan model pembelajaran LC 5E-TPS.

Lembar observasi digunakan untuk menjawab tujuan penelitian tentang keterlaksanaan proses pembelajaran. Keterlaksanaan proses pembelajaran digunakan untuk mengetahui model pembelajaran LC 5E-STAD dan LC 5E-TPS dapat terlaksana dengan baik atau tidak. Rancangan penelitian eksperimen semu ditunjukkan pada Tabel 1.

Tabel 1. Rancangan Penelitian Eksperimen Semu

\begin{tabular}{lcll}
\hline \multicolumn{1}{c}{ Subjek } & Perlakuan & Posttest \\
\hline Kelas LC 5E-STAD & $\mathrm{X}_{1}$ & $\mathrm{O}_{1}$ & \\
Kelas LC 5E-TPS & $\mathrm{X}_{2}$ & $\mathrm{O}_{2}$ & \\
\hline & & & (Sugiyono, 2010: 115)
\end{tabular}

\section{Keterangan:}

$\mathrm{O}_{1}$ : nilai hasil belajar kelas LC 5E-STAD

$\mathrm{O}_{2}$ : nilai hasil belajar kelas LC 5E-TPS

$\mathrm{X}_{1}$ : perlakuan pembelajaran dengan model LC 5E-STAD

$\mathrm{X}_{2}$ : perlakuan pembelajaran dengan model LC 5E-TPS

\section{Sampel dan Populasi}

Populasi dalam penelitian ini adalah semua siswa kelas XI SMAN 5 Malang Tahun Ajaran 2018/2019 yang terdiri dari 4 kelas dengan jumlah siswa 144 anak. Semua kelas mempunyai kemampuan yang sama. Kemampuan awal kelas diambil dari nilai materi sebelumnya. Sampel dalam penelitian ini diambil secara acak dengan undian dan diperoleh kelas XI E-4 sebagai kelas eksperimen yang dibelajarkan dengan model LC 5E-TPS dan kelas XI F-4 sebagai kelas eksperimen yang dibelajarkan dengan model LC 5E-STAD. Kedua kelas tersebut diberikan materi yang sama yaitu materi koloid. 


\section{Instrumen penelitian}

Instrumen yang digunakan dalam penelitian ini yaitu instrumen perlakuan dan instrumen pengukuran. Instrumen perlakuan terdiri dari silabus, RPP, dan LKS, sedangkan intrumen pengukuran terdiri dari lembar observasi yang digunakan untuk mengetahui keterlaksanaan proses pembelajaran dan soal tes hasil belajar yang digunakan untuk mengetahui hasil belajar kognitif siswa. Sebelum digunakan untuk pengambilan data, soal tes divalidasi dan dianalisis terlebih dahulu. Hasil uji coba selanjutnya dianalisis untuk mengetahui validitas, tingkat kesukaran, daya beda butir soal, dan reliabilitas tes.

\section{Pengumpulan data}

Langkah-langkah pengumpulan data yang ditempuh dalam penelitian ini meliputi tahap persiapan, tahap pelaksanaan, dan tahap akhir. Tahap persiapan yaitu melakukan observasi ke sekolah yang dituju untuk mengetahui gambaran umum proses pembelajaran yang dilaksanakan oleh guru serta menganalisis nilai hasil belajar siswa, menyusun silabus, RPP, dan LKS, menyusun dan mempersiapkan instrumen penelitian meliputi soal tes hasil belajar kognitif, melakukan uji prasyarat instrumen baik oleh validator ahli maupun uji coba kepada siswa. Pelaksanaan pembelajaran kimia pada materi koloid oleh peneliti dilakukan pada kedua kelas eksperimen. Pada kedua kelas eksperimen digunakan model pembelajaran yang berbeda. Kelas eksperimen yang satu menggunakan model pembelajaran LC 5E-STAD dan kelas eksperimen yang lain menggunakan model pembelajaran LC 5E-TPS. Perbedaan pada kedua model tersebut terletak pada jumlah anggota kelompok yang digunakan sehingga dimungkinkan adanya sumbangan pikiran yang berbeda-beda dari masing-masing kelompok. Kelas LC 5E-STAD terdapat empat sampai lima orang dalam tiap anggota kelompok sehingga sumbangan berpikir dari masing-masing siswa dapat terkumpul lebih banyak, sedangkan pada kelas LC 5E-TPS terdapat dua orang dalam tiap kelompok tetapi pada kelas LC 5E-TPS ini siswa diberi waktu untuk berpikir terlebih dahulu sebelum berkelompok. Kemudian tahap akhir yaitu setelah pembelajaran selesai, kedua kelas eksperimen diberi tes evaluasi yang berupa ulangan harian. Skor hasil belajar siswa pada materi koloid dikumpulkan dan dianalisis bersama nilai kuis, lembar observasi keterlaksanaan proses pembelajaran, penilaian afektif, penilaian psikomotorik.

\section{HASIL}

\section{Deskipsi dan Analisis Data Keterlaksanaan Pembelajaran LC 5E-STAD dan LC 5E-TPS}

Persentase keterlaksanaan pembelajaran diperoleh dari lembar observasi yang disusun dan dikembangkan dari langkah-langkah pembelajaran model LC 5E-STAD dan Model LC 5E-TPS. Kualitas proses pembelajaran diukur melalui observasi selama proses pembelajaran oleh observer untuk mengetahui keterlaksanaan tahap-tahap pada model pembelajaran yang digunakan. Data rata-rata keterlaksanaan proses pembelajaran kelas LC 5E-STAD dan kelas LC 5E-TPS dapat dilihat pada Tabel 2, sedangkan grafik rata-rata keterlaksanaan proses pembelajaran kelas $L C 5 E$ STAD dan kelas LC 5E-TPS dapat dilihat pada Gambar 1.

Tabel 2. Data Rata-rata keterlaksanaan proses pembelajaran kelas LC 5E-STAD dan kelas LC 5E-TPS

\begin{tabular}{lll}
\hline \multirow{2}{*}{ RPP } & \multicolumn{1}{c}{ Persentase Keterlaksanaan (\%) } \\
\cline { 2 - 3 } & Kelas $\boldsymbol{L C} \boldsymbol{C E}-\boldsymbol{T P S}$ & Kelas $\boldsymbol{L C} \mathbf{5 E - S T A D}$ \\
\hline Pertemuan 1 & 96,15 & 94,00 \\
Pertemuan 2 & 96,15 & 94,00 \\
Pertemuan 3 & 98,00 & 96,00 \\
Pertemuan 4 & 98,00 & 98,00 \\
Pertemuan 5 & 98,00 & 98,00 \\
\hline Rata-rata & $\mathbf{9 7 , 2 3}$ & $\mathbf{9 6 , 0 4}$ \\
\hline
\end{tabular}




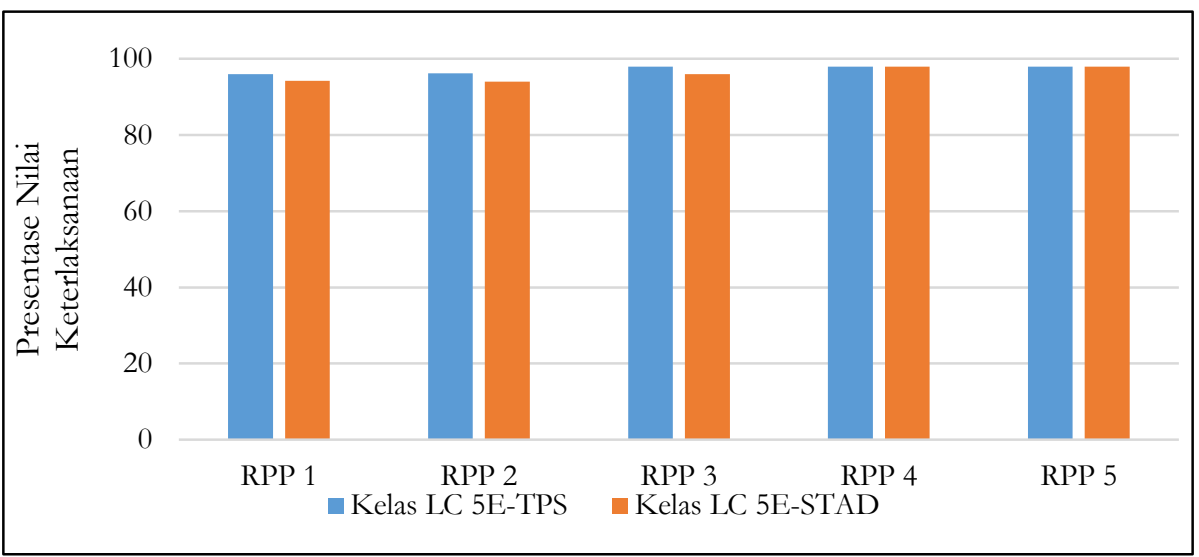

Gambar 1. Grafik rata-rata keterlaksanaan proses pembelajaran kelas LC 5E-STAD dan kelas LC 5E-TPS

Berdasarkan Tabel 2 dan Gambar 1 dapat disimpulkan bahwa keterlaksanaan proses pembelajaran dengan model pembelajaran LC 5E-STAD dan model pembelajaran LC 5E-TPS hampir sama dan dapat dikategorikan terlaksana dengan sangat baik. Hal ini dapat dilihat dari persentase rata-rata keterlaksanaan proses pembelajaran dari kelima RPP pada kelas LC 5E-STAD maupun kelas LC 5E-TPS sebesar $96,04 \%$ dan $97,23 \%$.

\section{Deskripsi dan Analisis Data Kemampuan Awal Siswa}

Data kemampuan awal siswa digunakan untuk mengetahui apakah kemampuan awal siswa pada kelas LC 5E-STAD dan LC 5E-TPS sama atau tidak. Deskripsi data kemampuan awal siswa yang dibelajarkan dengan LC 5E-STAD dan siswa yang dibelajarkan dengan LC 5E-TPS dapat dilihat pada Tabel 3.

Tabel 3. Deskripsi data kemampuan awal siswa yang dibelajarkan dengan LC 5E-STAD dan siswa yang dibelajarkan dengan LC 5E-TPS

\begin{tabular}{llllll}
\hline Kelas & $\begin{array}{l}\text { Jumlah } \\
\text { Siswa }\end{array}$ & $\begin{array}{l}\text { Nilai } \\
\text { Terendah }\end{array}$ & $\begin{array}{l}\text { Nilai } \\
\text { Tertinggi }\end{array}$ & Rata-rata & $\begin{array}{l}\text { Standar } \\
\text { Deviasi }\end{array}$ \\
\hline $\boldsymbol{L C} \boldsymbol{5} \boldsymbol{E}-\boldsymbol{S T A D}$ & 35 & 52 & 88 & 71,34 & 9,31 \\
$\boldsymbol{L C} \boldsymbol{5 E - T P S}$ & 34 & 56 & 84 & 70,06 & 7,42 \\
\hline
\end{tabular}

Tabel 3 menunjukkan bahwa rata-rata kemampuan awal siswa yang dibelajarkan dengan LC 5ESTAD sebesar 71,34 dan LC 5E-TPS sebesar 70,06 memiliki perbedaan rata-rata yang tidak signifikan. Kemudian dilakukan uji prasyarat yaitu uji normalitas dan uji homogenitas. Hasil uji normalitas data kemampuan awal siswa yang dibelajarkan dengan LC 5E-STAD dan siswa yang dibelajarkan dengan LC 5E-TPS dapat dilihat pada Tabel 4.

Tabel 4. Hasil uji normalitas data kemampuan awal siswa yang dibelajarkan dengan LC 5E-STAD dan Siswa yang dibelajarkan dengan LC 5E-TPS

\begin{tabular}{llll}
\hline Kelas & Nilai Signifikansi & $\boldsymbol{\alpha}$ & Kesimpulan \\
\hline LC 5E-STAD & 0,134 & 0,05 & Normal \\
LC 5E-TPS & 0,074 & 0,05 & Normal \\
\hline
\end{tabular}

Tabel 4 menunjukkan bahwa data kemampuan awal siswa yang dibelajarkan dengan LC 5E-STAD memiliki nilai signifikansi sebesar 0,134 yang lebih besar dari 0,05 dan kemampuan awal siswa yang dibelajarkan dengan LC 5E-TPS memiliki nilai signifikansi sebesar 0,074 yang lebih besar dari 0,05. 
Hasil uji homogenitas data kemampuan awal siswa yang dibelajarkan dengan LC 5E-STAD dan siswa yang dibelajarkan dengan LC 5E-TPS dapat dilihat pada Tabel 5.

Tabel 5. Hasil uji homogenitas data kemampuan awal siswa yang dibelajarkan dengan LC 5E-STAD dan siswa yang dibelajarkan dengan LC 5E-TPS

\begin{tabular}{lllll}
\hline Kelas & Nilai Rata-rata & Nilai Uji F Levene & Nilai Signifikansi & Kesimpulan \\
\hline LC 5E-STAD & 71,34 & 0,518 & 0,474 & Homogen \\
LC 5E-TPS & 70,05 & & & \\
\hline
\end{tabular}

Tabel 5 menunjukkan bahwa data kemampuan awal siswa yang dibelajarkan dengan LC 5E-STAD dan LC 5E-TPS memiliki varian yang sama atau homogen karena nilai signifikansinya $>0,05$ yaitu sebesar 0,474. Hasil uji prasyarat analisis menunjukkan bahwa data kemampuan awal siswa pada kedua kelas memiliki sebaran yang normal dan varian yang homogen. Selanjutnya dapat dilakukan uji kesamaan dua rata-rata menggunakan uji-t. Hasil uji kesamaan dua rata-rata kemampuan awal siswa yang dibelajarkan dengan LC 5E-STAD dan siswa yang dibelajarkan dengan LC 5E-TPS dapat dilihat pada Tabel 6.

Tabel 6. Hasil uji kesamaan dua rata-rata kemampuan awal siswa yang dibelajarkan dengan LC 5E-STAD dan Siswa yang dibelajarkan dengan LC 5E-TPS

\begin{tabular}{llll}
\hline Kelas & Nilai Rata-rata & Nilai signifikansi & Kesimpulan \\
\hline LC 5E-STAD & 71,34 & 0,529 & $\begin{array}{l}\text { Tidak ada perbedaan pada } \\
\text { kemampuan awal siswa }\end{array}$ \\
LC 5E-TPS & 70,05 & & \\
\hline
\end{tabular}

Tabel 6 menunjukkan bahwa tidak ada perbedaan kemampuan awal siswa yang dibelajarkan dengan LC 5E-STAD dan LC 5E-TPS karena nilai signifikansinya $>0,05$ yaitu sebesar 0,529. Dengan demikian dapat disimpulkan bahwa tidak terdapat perbedaan kemampuan awal siswa yang dibelajarkan dengan LC 5E-STAD dan LC 5E-TPS.

\section{Deskripsi dan Analisis Data Hasil Belajar Kognitif Siswa}

Data hasil belajar siswa digunakan untuk uji hipotesis. Data hasil belajar kognitif siswa diperoleh dari nilai ulangan harian (soal tes hasil belajar) materi koloid. Deskripsi data hasil belajar kognitif siswa yang dibelajarkan LC 5E-STAD dan siswa yang dibelajarkan LC 5E-TPS dapat dilihat pada Tabel 7.

Tabel 7. Deskripsi Data Hasil Belajar Kognitif Siswa yang Dibelajarkan LC 5E-STAD dan Siswa yang Dibelajarkan dengan LC $5 E-T P S$

\begin{tabular}{llllll}
\hline Kelas & $\begin{array}{l}\text { Jumlah } \\
\text { Siswa }\end{array}$ & $\begin{array}{l}\text { Nilai } \\
\text { Terendah }\end{array}$ & $\begin{array}{l}\text { Nilai } \\
\text { Tertinggi }\end{array}$ & Rata-rata & Standar Deviasi \\
\hline LC $\boldsymbol{5 E}$-STAD & 35 & 64 & 92 & 77,83 & 6,67 \\
$\boldsymbol{L C} \boldsymbol{5 E}-\boldsymbol{T P S}$ & 34 & 64 & 94 & 81,71 & 6,93 \\
\hline
\end{tabular}

Tabel 7 menunjukkan bahwa rata-rata hasil belajar kognitif siswa pada yaitu kelas LC 5E-TPS yaitu 81,71 lebih tinggi daripada kelas LC 5E-STAD yaitu 77,83. Sebelum dilakukan uji hipotesis, dilakukan uji prasyarat terlebih dahulu yaitu uji normalitas dan uji homogenitas. Hasil uji normalitas data hasil belajar kognitif siswa yang dibelajarkan LC 5E-STAD dan siswa yang dibelajarkan dengan LC 5E-TPS dapat dilihat pada Tabel 8. 
Tabel 8. Hasil uji normalitas data hasil belajar kognitif siswa yang dibelajarkan LC 5E-STAD dan siswa yang dibelajarkan dengan LC 5E-TPS

\begin{tabular}{llll}
\hline \multicolumn{1}{c}{ Kelas } & Nilai Signifikansi & $\alpha$ & Kesimpulan \\
\hline LC 5E-STAD & 0,72 & 0,05 & Normal \\
LC 5E-TPS & 0,99 & 0,05 & Normal \\
\hline
\end{tabular}

Tabel 8 menunjukkan bahwa data hasil belajar kognitif siswa terdistribusi normal atau memiliki sebaran data yang normal karena nilai signifikansinya $>0.05$ yaitu pada siswa yang dibelajarkan dengan LC 5E-STAD sebesar 0,72 dan pada siswa yang dibelajarkan dengan LC 5E-TPS sebesar 0,99 . Hasil uji homogenitas hasil belajar kognitif siswa yang dibelajarkan LC 5E-STAD dan siswa yang dibelajarkan dengan LC 5E-TPS dapat dilihat pada Tabel 9.

Tabel 9. Hasil uji homogenitas data hasil belajar kognitif siswa yang dibelajarkan LC 5E-STAD dan siswa yang dibelajarkan dengan LC 5E-TPS

\begin{tabular}{lllll}
\hline Kelas & Nilai Rata-rata & Nilai Uji F Levene & Nilai Signifikansi & Kesimpulan \\
\hline $\boldsymbol{L} \boldsymbol{C} \mathbf{5 E}-\boldsymbol{S T A D}$ & 77,83 & 0,002 & 0,969 & Homogen \\
$\boldsymbol{L} \boldsymbol{C} \boldsymbol{5} \boldsymbol{E}$ - $\boldsymbol{T P S}$ & 81,71 & & & \\
\hline
\end{tabular}

Tabel 9 menunjukkan bahwa data hasil belajar kognitif siswa yang dibelajarkan dengan LC 5ESTAD dan siswa yang dibelajarkan dengan LC 5E-TPS memiliki varian yang sama atau homogen karena nilai signifikansinya $>0,05$ yaitu sebesar 0,969 Hasil uji prasyarat analisis menunjukkan bahwa data hasil belajar kognitif siswa pada kedua kelas memiliki sebaran yang normal dan varian yang homogen. Selanjutnya dapat dilakukan uji hipotesis menggunakan uji-t. Hasil uji hipotesis hasil belajar kognitif siswa yang dibelajarkan dengan LC 5E-STAD dan siswa yang dibelajarkan dengan LC 5E-TPS dapat dilihat pada Tabel 10

Tabel 10. Hasil uji hipotesis hasil belajar kognitif siswa yang dibelajarkan dengan LC 5E-STAD dan siswa yang dibelajarkan dengan LC 5E-TPS

\begin{tabular}{llll}
\hline Kelas & Nilai Rata-rata & Nilai Signifikansi & Kesimpulan \\
\hline $\boldsymbol{L} \boldsymbol{C} \boldsymbol{5 E}-\boldsymbol{S T A D}$ & 77,83 & 0,021 & $\mathrm{H}_{0}$ ditolak \\
$\boldsymbol{L} \boldsymbol{C} \mathbf{5 E} \boldsymbol{T} \boldsymbol{T P S}$ & 81,71 & & \\
\hline
\end{tabular}

Kriteria terima $\mathrm{H}_{0}$ jika nilai signifikansi hasil pengujian $>0,05$. Berdasarkan Tabel 10 dapat disimpulkan bahwa $\mathrm{H}_{0}$ dapat ditolak sedangkan $\mathrm{H}_{1}$ diterima. Hal ini, menunjukkan bahwa ada perbedaan hasil belajar siswa yang dibelajarkan dengan LC 5E-STAD dan LC 5E-TPS. Rata-rata nilai hasil belajar pada materi koloid, menunjukkan bahwa siswa yang dibelajarkan dengan LC 5ETPS memiliki nilai rata-rata sebesar 81,71 yang lebih tinggi daripada nilai rata-rata siswa yang dibelajarkan dengan LC 5E-STAD sebesar 77,83

\section{PEMBAHASAN}

\section{Keterlaksanaan Pembelajaran LC 5E-STAD dan LC 5E-TPS pada Materi Koloid.}

Keterlaksanaan proses pembelajaran diamati sebanyak lima kali pertemuan sesuai dengan Rencana Pelaksanaan Pembelajaran (RPP). Proses pembelajaran, diamati oleh dua orang observer yaitu satu guru kimia SMAN 5 Malang, dan satu mahasiswa kimia Universitas Negeri Malang. Keterlaksanaan proses pembelajaran dilihat dari penilaian ketercapaian kegiatan pembelajaran yang telah direncanakan dalam Rencana Pelaksanaan Pembelajaran (RPP). 


\section{Hasil Belajar Siswa}

Rata-rata hasil belajar siswa yang dibelajarkan menggunakan model pembelajaran LC 5E-TPS yakni sebesar 81,71 sedangkan rata-rata hasil belajar siswa yang dibelajarkan menggunakan model pembelajaran LC 5E-STAD sebesar 77,83. Untuk mengetahui ada tidaknya perbedaan hasil belajar siswa yang dibelajarkan menggunakan model pembelajaran LC 5E-TPS dan model pembelajaran LC 5E-STAD dilakukan uji hipotesis dengan bantuan program SPSS Versi 25.0 for Windows. Hasil uji hipotesis menunjukkan nilai signifikansi sebesar 0,021 yang lebih kecil dari 0,05, sehingga dapat disimpulkan bahwa terdapat perbedaan hasil belajar siswa yang dibelajarkan menggunakan model pembelajaran LC 5E-TPS dengan siswa yang dibelajarkan menggunakan model pembelajaran LC 5E-STAD. Hasil belajar siswa yang dibelajarkan menggunakan model pembelajaran LC 5E-TPS lebih tinggi dibandingkan siswa yang dibelajarkan menggunakan model pembelajaran $L C 5 E$ STAD.

Hasil penelitian yang dilakukan oleh Aulia (2010) menunjukkan bahwa hasil belajar siswa yang diajar menggunakan model pembelajaran kooperatif tipe TPS lebih baik daripada siswa yang diajar dengan model pembelajaran kooperatif tipe $S T A D$. Proses pembelajaran pada siswa yang dibelajarkan dengan model pembelajaran LC 5E-TPS, dilakukan dengan siswa diberi pertanyaanpertanyaan penggali untuk dikerjakan secara individu. Guru menuntun siswa untuk menemukan jawaban-jawaban dari materi yang dipelajari. Siswa diberi kesempatan untuk berdiskusi dengan teman pasangannya untuk saling menukarkan informasi. Kegiatan ini menuntut siswa berpikir terlebih dahulu sebelum berdiskusi dengan temannya. Hal ini menyebabkan setiap siswa berusaha menemukan konsep dari materi yang dipelajari baru kemudian saling bertukar gagasan dengan teman pasangannya untuk mencari konsep yang lebih benar dari materi yang dipelajar. Oleh sebab itu, hasil belajar siswa yang dibelajarkan menggunakan model pembelajaran LC 5E-TPS cenderung lebih tinggi dibandingkan dengan siswa yang dibelajarkan dengan menggunakan model pembelajaran LC 5E-STAD.

Model pembelajaran LC 5E-STAD mengharuskan adanya penghargaan kelompok dan skor kemajuan individu. Penghargaan kelompok dan skor kemajuan individu merupakan ciri dari model pembelajaran kooperatif tipe STAD. Skor kemajuan individu setiap kelompok merupakan rata-rata dari skor kemajuan individu dari seluruh anggota kelompok yang digunakan untuk penentuan penghargaan yang diterima oleh kelompok. Penghargaan kelompok dilakukan sebanyak lima kali pada setiap pertemuan. Pertemuan pertama diperoleh 2 kelompok baik dan 6 kelompok hebat. Pertemuan kedua diperoleh 4 kelompok hebat, dan 4 kelompok baik. Pertemuan yang ketiga diperoleh 2 kelompok super dan 5 kelompok hebat serta 1 kelompok baik. Pertemuan keempat mengalami peningkatan yaitu diperoleh 1 kelompok super dan 6 kelompok hebat serta 1 kelompok baik. Pertemuan kelima mengalami peningkatan terdapat 2 kelompok super dan 6 kelompok hebat. Penghargaan kelompok yang diberikan kepada kelompok dapat memotivasi kelompok lain untuk meningkatkan kerja sama sehingga memperoleh hasil yang lebih baik.

Rata-rata nilai afektif pada siswa yang dibelajarkan dengan model pembelajaran LC 5E-TPS sebesar 75,27 lebih tinggi daripada siswa yang dibelajarkan dengan model pembelajaran LC 5E-STAD yakni sebesar 73,16 . Perbedaan rata-rata nilai afektif ini, karena siswa yang dibelajarkan dengan menggunakan model pembelajaran LC 5E-TPS kondisi kelas lebih terstruktur, adanya kerja sama dengan teman pasangannya ( 2 orang) sehingga kesempatan menyampaikan pendapat lebih besar dibandingkan siswa yang dibelajarkan dengan menggunakan model pembelajaran LC 5E-STAD yang kelompoknya beranggotakan empat sampai lima orang yang dapat menyebabkan keramaian saat berdiskusi atau mendiskusikan hal lain diluar materi yang sedang dipelajari. Susilo dalam (Primandiri,2009: 18) mengatakan ada beberapa kelebihan dalam penggunaan pembelajaran kooperatif TPS yaitu (1) Pembelajaran kooperatif TPS membantu menstrukturkan diskusi. Hal ini disebabkan dalam pembelajaran kooperatif TPS tahapan-tahapan yang digunakan dalam menyelesaikan pertanyaan tersusun sangat beruntun dari individu, berpasangan, dan berbagi; (2) Pembelajaran kooperatif TPS meningkatkan partisipasi siswa dan meningkatkan banyaknya 
informasi yang dapat diingat sisa; (3) pembelajaran kooperatif TPS meningkatkan lamanya "time on task" dalam kelas dan kualitas kontribusi dalam diskusi kelas; (4) siswa dapat mengembangkan kecakapan hidup sosialnya.

Hasil belajar ranah psikomotorik adalah ranah yang berkaitan dengan keterampilan skill atau kemampuan bertindak setelah orang menerima pengalaman belajar tertentu. Hasil belajar psikomotorik ini sebenarnya merupakan kelanjutan dari hasil belajar kognitif dan afektif (Sagala,2010:160). Rata-rata nilai psikomotorik pada siswa yang dibelajarkan dengan model pembelajaran LC 5E-TPS sebesar 86,02 dan siswa yang dibelajarkan dengan LC 5E-STAD sebesar 85,31. Dengan demikian dapat disimpulkan bahwa nilai psikomotorik siswa yang dibelajarkan $L C$ 5E-TPS lebih baik dari siswa yang dibelajarkan dengan LC 5E-STAD. Perbedaan rata-rata psikomotorik ini, terjadi karena siswa yang dibelajarkan dengan menggunakan LC 5E-TPS dengan anggota kelompok yang lebih sedikit siswa nampak lebih bertanggung jawab pada pembelajarannya.

Keaktifan siswa nampak meningkat pada saat mengikuti proses pembelajaran. Siswa yang dibelajarkan dengan LC 5E-STAD, pada waktu melakukan diskusi tidak semua anggota kelompok melakukan diskusi, sebagian ada yang melihat temannya. Siswa yang dibelajarkan dengan $L C 5 E$ $S T A D$ memperoleh nilai yang rendah, karena hanya beberapa siswa saja yang bekerja keras dalam menyelesaikan tugas sedangkan siswa lainnya cenderung pasif.

\section{KESIMPULAN}

Dari hasil penelitian dan pembahasan yang telah diuraikan didapatkan kesimpulan:

1. Keterlaksanaan proses pembelajaran pada model pembelajaran LC 5E-TPS rata-rata sebesar $97,23 \%$. Keterlaksanaan proses pembelajaran pada model pembelajaran LC 5E-STAD sebesar $96,04 \%$. Keterlaksanaan proses pembelajaran ini termasuk tergolong terlaksana dengan sangat baik.

2. Terdapat perbedaan hasil belajar siswa yang dibelajarkan menggunakan model pembelajaran LC 5E-TPS dengan siswa yang dibelajarkan dengan menggunakan model pembelajaran LC 5E-STAD. Rata-rata hasil belajar siswa yang dibelajarkan menggunakan model pembelajaran LC 5E-TPS yaitu sebesar 81,71 lebih tinggi daripada hasil belajar siswa yang dibelajarkan menggunakan model pembelajaran LC 5E-STAD yaitu sebesar 77,83.

Dari hasil penelitian yang sudah dilakukan, maka saran yang diberikan adalah:

1. Penelitian ini hanya mengkaji hasil belajar siswa yang dibelajarkan menggunakan model pembelajaran LC 5E-STAD dan model pembelajaran LC 5E-TPS, sehingga untuk penelitian selanjutnya perlu dikaji pengaruh penerapan model pembelajaran LC 5E-STAD dan model pembelajaran LC 5E-TPS dengan variabel lainnya, misalnya pada motivasi belajar siswa.

2. Jika ada peneliti lain yang tertarik mengkaji hasil belajar siswa yang dibelajarkan menggunakan model pembelajaran LC 5E-STAD dan model, pembelajaran LC 5E-TPS, maka kreativitas dan keterampilan guru sangat diperlukan dalam manajemen kelas dan manajemen waktu yang baik agar kegiatan pembelajaran berlangsung sesuai dengan yang telah direncanakan.

\section{DAFTAR RUJUKAN}

Aulia, F. S. (2010). Perbandingan Model Pembelajaran STAD (Student Teams Achievement Divisions) dengan TPS (Think Pair Share) dalam Materi Zat Aditif Makanan, Zat Adiktif, dan Psikotropika pada Siswa Kelas VIII SMP Negeri 15 Malang Semester Genap Tahun Ajaran 2009/2010. Skripsi tidak diterbitkan. Malang: FMIPA Universitas Negeri Malang.

Daro'aini \& Faizatul. (2013). Pengaruh Kemampuan Memahami Bacaan, Kemampuan Memori, dan Kemampuan Analisis Terhadap Prestasi Belajar Siswa Pada Materi Koloid Kelas XI Semester Genap SMA Negeri 1 Ngemplak Tahun Pelajaran 2012/2013. Jurnal Pendidikan Kimia. 2(3): 139-145.

Effendy. (2006). A-Level Chemistry for Senior High School Students Volume 1A. Malang: Bayumedia. 
Fajaroh, F. \& Dasna, I W. (2007). Pembelajaran dengan Model Siklus Belajar (Learning Cycle), (Online), (http://lubisgrafura.wordpress.com/2007/09/20/pembelajaran-dengan- model-siklus-belajarlearning-cycle/), diakses 20 Mei 2018

Herbandri. (2008). Penerapan Paduan Model Pembelajaran Daur Belajar (Learning Cycle) dan Kooperatif Tipe STAD untuk. Meningkatkan Kualitas Proses dan Hasil Belajar Kimia. Tesis tidak diterbitkan. Malang: PPs UM.

Iskandar, S.M. (2011). Pendekatan Pembelajaran Sains Berbasis Konstruktivis. Malang: Bayumedia Publishing.

Jatmiko, H. S. (2014). Perbedaan Hasil Belajar Materi Asam-Basa antara Siswa yang Dibelajarkan dengan Model Pembelajaran Learning Cycle 5E dengan Learning Cycle 5E-Think Pair Share pada Siswa Kelas XI SMAN 1 Gondang Tulungagung. Skripsi tidak diterbitkan: FMIPA Universitas Negeri Malang.

Kementrian Pendidikan dan Kebudayaan. (2016). Lampiran 09 KI dan KD Kimia Permendikbud Nomor 24 Tabun 2016. Jakarta: Kementrian Pendidikan dan Kebudayaan.

Primandiri, P. (2009). Penerapan Pembelajaran Kooperatif Think Pair Share (TPS) untuk Meningkatkan Kemampuan Berpikir dan Hasil Belajar Biologi Siswa Kelas X-8 SMA Negeri 7 Malang. Skripsi. Tidak diterbitkan. Malang: UM.

Sagala, S. (2010). Konsep dan Makna Pembelajaran. Bandung: Alfabeta

Setyowati. (2011). Pengarub Penggunaan Model Pembelajaran Learning Cycle-STAD terbadap Prestasi Belajar Siswa Kelas X SMA Negeri 9 Malang Pada Materi Minyak Bumi Tabun Ajaran 2010/ 2011. Skripsi tidak diterbitkan: FMIPA Universitas Negeri Malang.

Slavin, Robert E. (2005). Cooperative Learning: Teori, Riset dan Praktek. Bandung: Nusa Media.

Sugiyono. (2014). Metode Penelitian Kuantitatif, Kualitatif dan R\&D. Bandung: Alfabeta. 